\title{
Conversion of Multiple Forms of Chondroitinase AC from Arthrobacter aurescens
}

\author{
Keiichiro Hiyama and Shigetaka OKada \\ Department of Biochemistry, Osaka Municipal Technical Research Institute, \\ 1-1, Oogimachi 2-chome, Kita-ku, Osaka, Osaka 530, Japan \\ Received February 28, 1978
}

\begin{abstract}
Immunochemical identification certified the electrophoretically separable components of Arthrobacter chondroitinase to be the multiple forms of chondroitinase AC.

The electrophoretic patterns of the enzyme preparations obtained at various cultivation stages showed that chondroitinase III is produced at first and the multiple forms of the chondroitinase occur during cultivation of the strain. In mature culture, chondroitinase I was the main component among the multiple forms.

From the conversion experiments using the supernatant fluid of chondroitinase-free culture broth and uridine-5'-diphospho-D-glucose and using glycosidases from Charonia lampas, chondroitinase I and chondroitinase II, respectively, seemed to arise from glucosylation of chondroitinase III and from de-glycosylation of chondroitinase III or I.
\end{abstract}

Our previous study ${ }^{17}$ has shown the presence of multiple forms of chondroitinase AC[chondroitin AC lyase, EC 4.2.2.5] in the enzyme preparation which was obtained from the culture broth of Arthrobacter aurescens cultivated in a jar fermentor and then was purified by the chromatography on SE-Sephadex and Sephadex $G-100$. The separation of the multiple forms of this enzyme was accomplished by electrophoresis and the three fractions were designated chondroitinase I $(\mathrm{pI}=5.6)$, chondroitinase II $(\mathrm{pI}=5.8)$, and chondroitinase III $(\mathrm{pI}=6.4)$. There was no detectable difference in the enzymic properties of those fractions including the substrate specificity, the stable and optimal conditions, the mode of action, and the molecular weight values. However, a slight difference was detected in the carbohydrate contents of those fractions.

On the other hand, the purified chondroitinase preparation which had been obtained from the culture broth in mature culture, shaking culture for $48 \mathrm{hr}$, has already been found to be electrophoretically homogeneous ${ }^{2)}$ and to correspond to chondroitinase $\mathrm{I}^{13}$ Though the multiple forms were estimated to be caused from the variation of carbohydrate content of the enzyme during cultivation, the real reason was still not clear from those results alone.

Accordingly, to clarify the relationship between the age of $A$. aurescens and the multiple forms of the chondrotinase, the changes in the enzyme activity of the forms were investigated during cultivation in a jar fermentor. Furthermore, the conversion of the multiple forms of the enzyme was investigated in vitro.

The present paper describes these results.

\section{MATERIALS AND METHODS}

Materials. The chemicals used in this study were purchased: bonito extract (Wako Pure Chemical Industry), polypeptone (Daigoeiyo Chem. Co.), chondroitin sulfate C (Seikagaku Kogyo Co.), alcian blue (ChromaGesellschaft, Schmid \& Co.), uridine-5'-diphospho-Dglucose (UDP-Glc) and guanosine-5'diphospho-Dmannose (GDP-Man) (Kyowa Hakko Co.), and UDPGlc composed of unitary ${ }^{14} \mathrm{C}$-labeled glucose (UDP[14 C(U)]-Glc, $200 \mathrm{mCi} / \mathrm{mmol}$ ) (New England Nuclear). Glycosidases from the liver of Charonia lampas were kindly provided by Seikagaku Kogyo Co. as a mixture, which (1 g) contained $\alpha$-glucosidase [EC 3.2.1.20] (1 enzyme unit), $\beta$-glucosidase [EC 3.2.1.21] (7.2 enzyme unit), $\alpha$-mannosidase [EC 3.2.1.24] (19 enzyme unit), $\beta$-mannosidase [EC 3.2.1.25] (4 enzyme unit), $\alpha$-galactosidase [EC 3.2.1.22] (6.4 enzyme unit), $\beta$-galactosidase [EC 3.2.1.23] (15 enzyme unit), $\alpha$-L-fucosidase [EC 3.2.1.51) (5.9 enzyme unit), $\beta$-xylosidase [EC 3.2.1.37] (7.8 enzyme unit), $\beta$-N-acetylglucosaminidase [EC 3.2.1.30] (61 enzyme unit), $\alpha$-N-acetylgalactosaminidase 
[EC 3.2.1.49] (16 enzyme unit), and $\beta$ - $\mathrm{N}$-acetylgalactosaminidase [EC 3.2.1.52] (10 enzyme unit). The activities were measured by use of $p$-nitrophenylglycosides as the substrates except that $\alpha$ - and $\beta$ - $\mathrm{N}$-acetylgalactosaminidases' activities were measured by use of phenyl$\mathrm{N}$-acetylgalactosaminides.

Cultivation of the strain and preparation of the enzyme. Cultivation of Arthrobacter aurescens was carried out in a bouillon-chondroitin sulfate medium which was composed of $0.4 \%$ bonito extract, $0.4 \%$ polypeptone and $0.2 \%$ chondroitin sulfate $\mathrm{C}$, and adjusted to $\mathrm{pH} 5.8$ with $\mathrm{HCl}$. The strain $A$. aurescens IAM 11065 was grown at $30^{\circ} \mathrm{C}$ in a $500-\mathrm{ml}$ shaking flask containing $50 \mathrm{ml}$ of the medium for $48 \mathrm{hr}$. Then the culture broth $150 \mathrm{ml}$ was inoculated to 15 liters of the same medium as above and the bacterium was cultivated at $30^{\circ} \mathrm{C}$ in a 30 -liter jar fermentor with aeration (5 liters/ $\mathrm{min}$ ) and agitation $(180 \mathrm{rpm})$. At predetermined times the culture broth $200 \mathrm{ml}$ was withdrawn and then the chondroitinase was collected by ammonium sulfate precipitation $(0 \sim 0.75$ saturation). After dissolution and dialysis the crude enzyme solution was subjected to chromatography on a column of SP-Sephadex (2.0x $45 \mathrm{~cm}$ ) equilibrated with $0.02 \mathrm{M}$ acetate buffer $(\mathrm{pH} 5.2)$ under the same conditions as described in our previous paper. $^{2)}$

Preparation of chondroitinase-free culture broth and cell homogenate. Arthrobacter aurescens was grown in a medium containing $0.4 \%$ polypeptone, $0.4 \%$ bonito extract, and $0.2 \%$ glucose at the initial pH 6.2. After shaking for 2 days at $30^{\circ} \mathrm{C}$ in a $500-\mathrm{ml}$ shaking flask, a chondroitinase-free culture broth was obtained. Then the broth was centrifuged to separate into cells and the supernatant fluid. The cells were washed 3 times by $10 \mathrm{ml}$ of water and homogenated by ultrasonic oscillator. The homogenate was collected.

Immunochemical procedure. Rabbit antiserum was prepared against the fractionated chondroitinase III as follows: firstly, the mixture of the purified chondroitinase III solution $(0.8 \mathrm{mg}$ in $0.4 \mathrm{ml}$ of water) and the complete Freundary adjuvant $(0.4 \mathrm{ml}$, Iatron Lab.) was injected hypodermically at foot pads of a rabbit: secondly, after 3 weeks the enzyme solution $(4 \mathrm{mg}$ in $2 \mathrm{ml}$ of water) was injected at the muscle of the rabbit; thirdly, 2 weeks thereafter the enzyme solution $(4 \mathrm{mg}$ of the enzyme in $4 \mathrm{ml}$ of the physiological solution of sodium chloride) was injected into the veins of the rabbit; 2 weeks after the 3 rd injection the whole blood was drawn out and the $\gamma$-globulin fraction was obtained by means of coagulation of fibrin and centrifugation.

Ouchterlony double-diffusion was performed as described by Ouchterlony. ${ }^{3)}$

Analytical methods. Buffer concentration was deter- mined by measurement of electric conductance of the solution by use of a Toa Dempa Kogyo Co. conductometer (model CM-1DB). Immunoelectrophoretic analysis was performed on an agar plate $(2.5 \times 7.5 \mathrm{~cm})$ at $\mathrm{pH} 5.0$ and $1 \mathrm{~mA} /$ plate for $2 \mathrm{hr}$ according to the method of Scheidegger. ${ }^{3)}$ Polyacrylamide gel plate isoelectric focusing was performed at 2.5 to 10 watts, $10^{\circ} \mathrm{C}$ using a Ampholine PAG plate (pH 3.5 9.5, LKB Produkter $\mathrm{AB}$ ). After isoelectric focusing for $2 \mathrm{hr}$, a strip of cellulose acetate membrane $(6 \times 7 \mathrm{~cm}$, Separax, Joko Sangyo Co.) which had previously been immersed in $0.1 \%$ chondroitin sulfate $\mathrm{C}$ was applied in the wet state over the gel and incubated at $40^{\circ} \mathrm{C}$ for $30 \mathrm{~min}$. The membrane was dried and stained with alcian blue according to the method of Seno et al. By this procedure the enzymes were located at white areas against a blue background (shaded area) (see Fig. 4). Usual column isoelectric focusing in $\mathrm{pH}$ and density gradient was performed by the method of Vesterberg and Svensson. ${ }^{5)}$ Paper chromatography was carried out using Toyo No. $50(40 \times 40 \mathrm{~cm})$ paper developed twice by the ascending technique in $I$. butanol: pyridine: water ( $6: 4: 3$ by volume). Each spot of reducing sugar on the paper chromatogram was detected by silver nitrate method. ${ }^{6)}$

Enzyme assay. Chondroitinase activity was assayed by the same method as described in the previous paper.2) The enzyme unit is defined as equal to the reducing power of unsaturated disaccharides at $\mathrm{pH} 6.0(0.05 \mathrm{M}$ acetate buffer). Other enzymes' activities were represented by the amount of liberated reducing sugar $(\mu \mathrm{mol})$ per min at $37^{\circ} \mathrm{C}$.

\section{RESULTS AND DISCUSSION}

\section{Immunochemical analysis}

Electrophoretically separable components (chondroitinase I, II, and III) obtained in the previous study were subjected to immunochemical analyses in order to ascertain that the components are immunochemically identical multiple forms. Figure 1a shows the Ouchterlony double-diffusion pattern obtained when antibody prepared against purified chondroitinase III was allowed to react with each chondroitinase component. Complete fusions of the lines were observed. The immunoelectrophoretic patterns of every components showed simple symmetrical lines of precipitation (Fig. 1b). Thus it seems that no difference exists in the immunochemical characters of three chondroitinase components. 


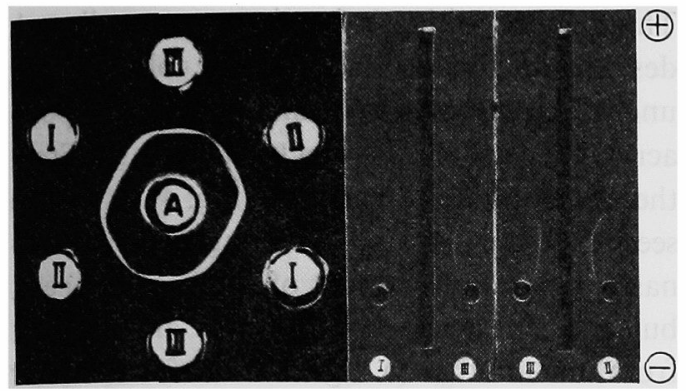

(a)

(b)

FIG. 1. Ouchterlony Double-diffusion Analysis (a) and Immunoelectrophoretic Patterns (b) of Three Chondroitinase Fractions (I, II, and III).

(a) The center well contained $0.4 \mathrm{mg}$ of anti-(chondroitinase III) $\gamma$-globulin. The perpheral wells contained $40 \mu \mathrm{g}$ of the fractionated chondroitinases. (b) After electrophoresis of each chondroitinase $(40 \mu \mathrm{g})$ $0.8 \mathrm{mg}$ of anti-(chondroitinase III) $r$-globulin was placed in the troughs. Experimental details are described in Materials and Methods.

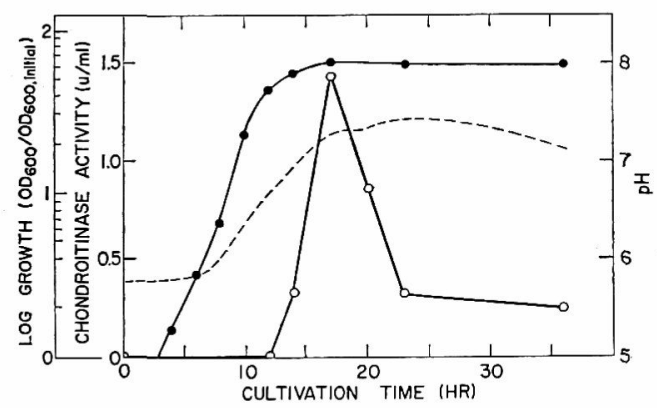

FIG. 2. Growth Curve and Chondroitinase Activity in the Supernatant Fluid of Culture Broth during Cultivation in a Jar Fermentor.

The culture medium contained $0.4 \%$ polypeptone, $0.4 \%$ bonito extract and $0.2 \%$ chondroitin sulfate C. Cultivation was carried out at $30^{\circ} \mathrm{C}$ with aeration (10liters $/ \mathrm{ml}$ ) and aggitation (180 rpm). - - growth (logarithmic value of the ratio of absorbance at $600 \mathrm{~nm}$ to the initial value); $\mathrm{O}-\mathrm{O}$, chondroitinase activity; ---, $\mathrm{pH}$ value of the medium.

\section{Changes in the ratio of multiple forms during cultivation}

The growth of Arthrobacter aurescens and the chondroitinase activity in the supernatant fluid were measured at various stages when the bacterium was grown in a jar fermentor containing a bouillon-chondroitin sulfate medium. As shown in Fig. 2, it was found that the chondroitinase activity became maximum at the early stage of the stational phase of cell growth. The result suggests that the chondroitinase protein is no longer produced and undergoes the subsequent denaturation after the stage. After precipitation with ammonium sulfate and dialysis against deionized water the crude enzyme solutions obtained at 14, 17, 20, and $23 \mathrm{hr}$ cultivation times were adsorbed on SP-Sephadex and eluted by a linear gradient of acetate buffer ( $\mathrm{pH}$ 5.2) concentration. The elution patterns are shown in Fig. 3. The peaks of chondroitinase activity appeared at the buffer concentration of $0.136 \mathrm{M}$ for the 14 -hr aged preparation, $0.128 \mathrm{M}$ for 17 -hr aged one, $0.113 \mathrm{M}$ for $20-\mathrm{hr}$ aged one, and $0.117 \mathrm{M}$ for 23-hr aged one. Thus it seems that the isoelectric point of the chondroitinase becomes lower as the cultivation time becomes longer.

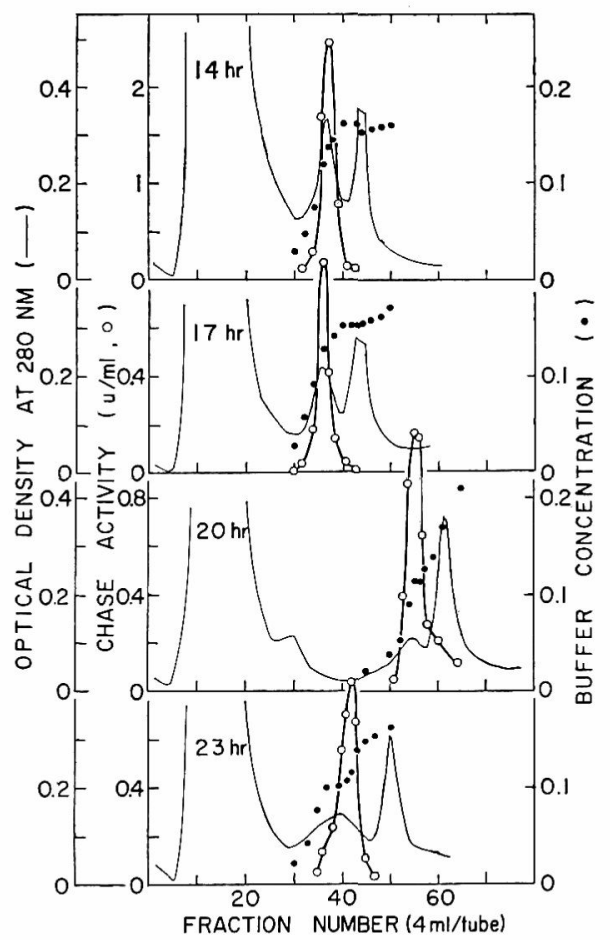

FIg. 3. Elution Patterns of Variously Aged Chondroitinase from SP-Sephadex.

The chondroitinase preparations were obtained at various cultivation stage $(14,17,20$, and $23 \mathrm{hr}$ ). The experimental procedure is described in the text. $\mathrm{O}-\mathrm{O}$, chondroitinase activity; - - optical density at $280 \mathrm{~nm}$; , buffer concentration. 


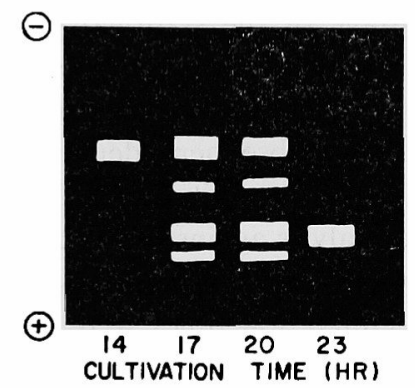

FIG. 4. Changes in the Electrophoretic Patterns of Arthrobacter Chondroitinase during Cultivation.

Electrophoresis was carried out on a polyacrylamide gel plate $(7.5 \times 10 \mathrm{~cm})$ containing Ampholine carrier ampholytes (pH $3.5 \sim 9.5)$ at $2.5 \sim 10$ watts, $10^{\circ} \mathrm{C}$. Then the chondroitinase activity located in the gel was detected by means of replication to a cellulose acetate membrane which had been immersed in chondroitin sulfate solution. Experimental details are described in the text.

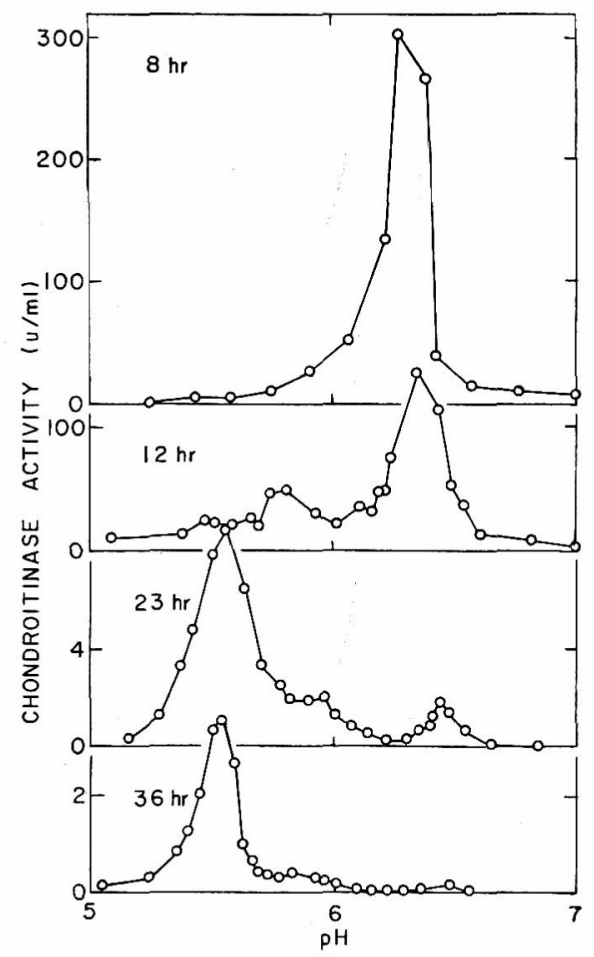

FIG. 5. Electrophoretic Patterns of Four Chondroitinase-preparations Obtained at the Cultivation Time Shown in the Figures.

Electrophoresis was carried out in a $100-\mathrm{ml}$ column containing Ampholine carrier ampholytes pH 4 to 8 ( $1 \%$ by volume) for $40 \mathrm{hr}$ at 500 to 700 volts, 1.8 to $11 \mathrm{~mA}, 4^{\circ} \mathrm{C}$. Then the fractions were collected ( $2 \mathrm{ml}$ per tube).
These chondroitinase fractions were collected, desalted and concentrated with a collodion bag under reduced pressure, and subjected to polyacrylamide gel plate isoelectric focusing. From the electrophoretic patterns (Fig. 4), it can be seen that the 14- and 23-hr aged chondroitinase preparations consist of single component, but the isoelectric point values are different from one another (a higher value for the 14-hr aged enzyme and a lower value for 23-hr aged enzyme), while the preparations obtained at middle stages were found to consist of various chondroitinase components. Figure 5 shows the typical electrophoretic patterns of the chondroitinase preparations which were obtained in large amount after cultivation for various time in a jar fermentor. The 8- and 12-hr aged preparations were obtained when $750 \mathrm{ml}$ of the seed culture broth had been inoculated to 15 liters of the fresh culture medium (adjusted the initial pH to 6.2). These results show that the isoelectric point of the chondroitinase in young culture is the higher value ( $\mathrm{pI}=6.4$, named chondroitinase III) and that of the enzyme in mature culture is the lower value $(\mathrm{pI}=5.5$, named chondroitinase $\mathrm{I})$. In the middle stage of culture there were at least three fractions including chondroitinase II $(\mathrm{pI}=5.9)$ other than chondroitinase I and III. Thus it seems that chondroitinase III has been converted into chondroitinase I or II in the culture medium during cultivation of the bacterium.

\section{Conversion of the multiple forms of chondroiti- nase in vitro}

The chondroitinase-free culture broth of $A$. aurescens IAM 11065 was obtained by the procedure described in MATERIALS AND METHODS. The culture broth was divided into the supernatant fluid and the cells by centrifugation at $15,000 \times g$ for $15 \mathrm{~min}$. Then three portions of the purified chondroitinase III (100 enzyme unit, $3 \mathrm{mg}$ ) obtained in young culture were incubated with the supernatant fluid, the cell homogenate and the culture broth, respectively. After 24-hr incubation at room temperature and separation from cells those enzyme solu- 


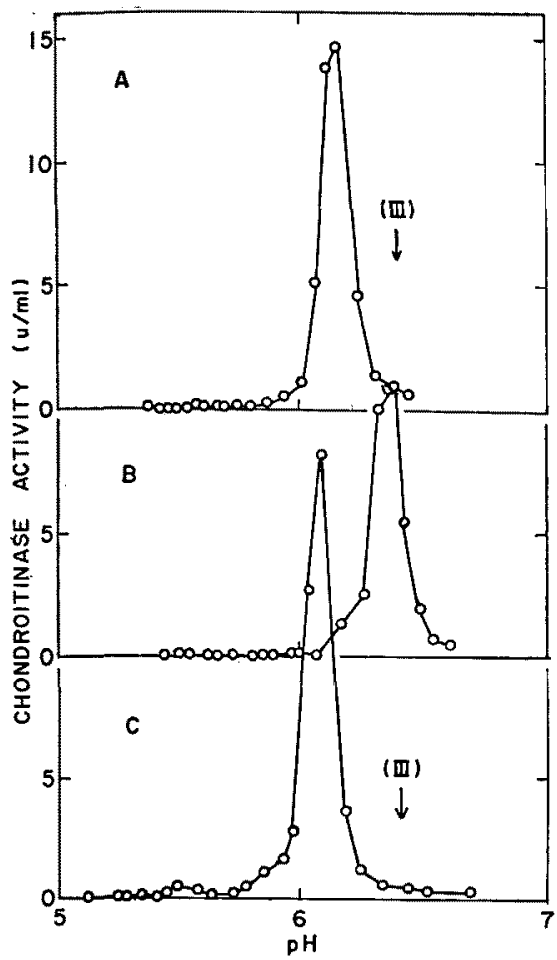

FIg. 6. Alteration in the Isoelectric Point of Chondroitinase III after Incubation with the Supernatant Fluid of Chondroitinase-free Culture Broth (A), Cell homogenate (B), and the Culture Broth (C).

Chondroitinase III (100 enzyme unit, $3 \mathrm{mg}$ ) was incubated at $\mathrm{pH} 6.0$, room temperature for $24 \mathrm{hr}$ with $50 \mathrm{ml}$ of the supernatant fluid, cell homogenate (see text), or the culture broth.

tions were dialyzed against deionized water, concentrated to $2 \mathrm{ml}$ using a collodion bag, and subjected to isoelectric focusing. The electrophoretic patterns are shown in Fig. 6. Although any changes were not detected in the case of incubation with the cell homogenate, the conversion of chondroitinase III into chondroitinase II was observed when chondroitinase III was incubated with the culture broth or its supernatant fluid. It was also observed that the culture broth slightly converts chondroitinase III into chondroitinase I and the cell homogenate makes some portions of chondroitinase III inactive.

Since the conversion of chondroitinase III into chondroitinase I was thought to be caused by addition of sugar residues as described in the previous paper, ${ }^{1)}$ chondroitinase III was incubated with the supernatant fluid of the culture broth in the presence of UDP-Glc or GDP-Man. As shown in Fig. 7, chondroitinase III was apparently converted into chondroitinase $I$ in the presence of UDP-Glc and the supernatant fluid of culture broth. When UDP- $\left[{ }^{14} \mathrm{C}(\mathrm{U})\right]-\mathrm{Glc}$ was used in addition to cold one, the radio activities were electro-focused into the fractions of chondroitinase I. From the result shown in Fig. 7, it was estimated that about 6 moles of glucose had been bound to one mole of the chondroitinase. On the other hand, there were not any changes on the case of incubation of chondroitinase III with GDP-Man. Therefore, the conversion of chondroitinase III into chondroitinase I seems to be caused by binding of glucose residues.

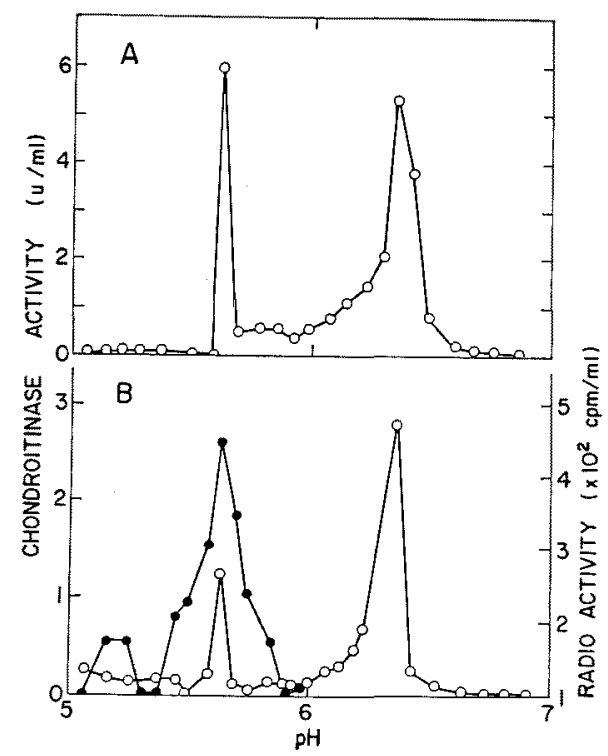

FIG. 7. Alteration in the Isoelectric Point of Chondroitinase III after Incubation with the Supernatant Fluid of Chondroitinase-free Culture Broth in the Presence of UDP-Glc (A) or UDP- $\left[{ }^{14} \mathrm{C}(\mathrm{U})\right]-\mathrm{Glc}(\mathrm{B})$.

The incubation mixture of the experiment A contained 100 units of the enzyme $(3 \mathrm{mg}), 500 \mu \mathrm{g}$ of UDP-Glc, and $50 \mathrm{ml}$ of the supernatant fluid of which $\mathrm{pH}$ value was adjusted to 6.0. The incubation mixture of the experiment $\mathrm{B}$ contained $0.06 \mu \mathrm{Ci}$ of UDP $-\left[{ }^{14} \mathrm{C}(\mathrm{U})\right]-\mathrm{GlC}$ in addition to the incubation mixture of $\mathrm{A}$ (the final radio-specific activity was $0.068 \mathrm{mCi} / \mathrm{mmol}$ ). Experimental details are described in the text. 


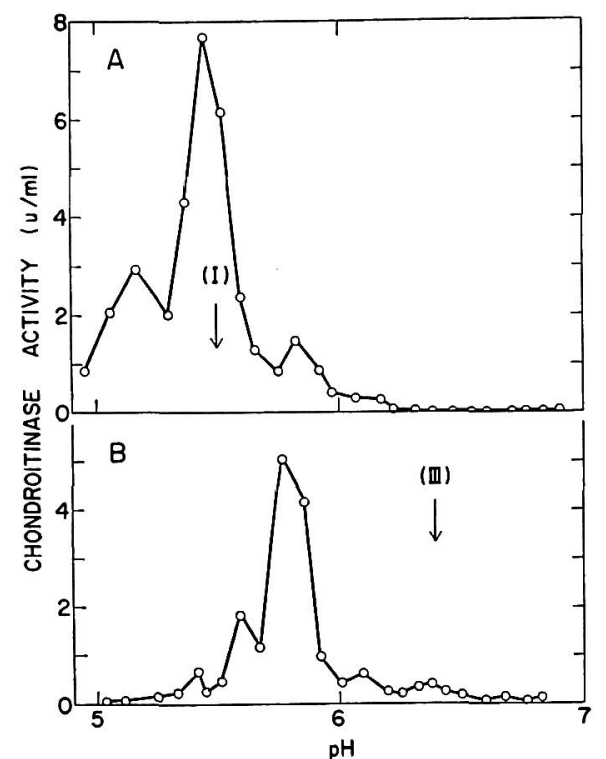

FIG. 8. Alteration in the Electrophoretic Patterns of Chondroitinase I and III after Incubation with the Glycosidases from Charonia lampas.

Chondroitinase I (A) and III (B) were, respectively, incubated into $5 \mathrm{ml}$ of $0.02 \mathrm{M}$ acetate buffer (pH 5.2) containing $2 \mathrm{mg}$ of the glycosidases preparation. Experimental details are described in the text.

Furthermore, chondroitinase I and III (100 enzyme unit, $3 \mathrm{mg}$ ), respectively, were incubated with the mixture of glycosidases $(2 \mathrm{mg})$ in

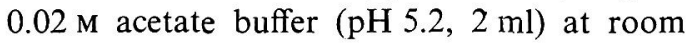
temperature for $24 \mathrm{hr}$. Then the incubation mixture was filtered on a collodion bag under reduced pressure. The residual enzyme solution was subjected to isoelectric focusing. The filtrate was concentrated under reduced pressure and then subjected to paper chromatography. Figure 8 shows the electrophoretic patterns of the incubated enzymes. Most of the chondroitinase III was converted into

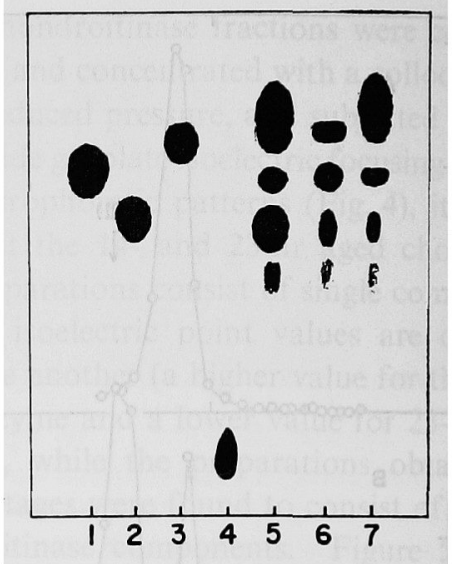

FIG. 9. Paper Chromatography of Reducing Sugars Liberated from Chondroitinase I and III by the Action of the Glycosidases from Charonia lampas.

Color development was carried out by the silver nitrate method ${ }^{8)}$ after developing twice by the ascending technique in the solvent system of 1-butanolpyridine-water ( $6: 4: 3$ by volume). 1 , mannose; 2, glucose; $3, \mathrm{~N}$-acetylglucosamine; 4 , glucuronic acid; 5 , filtrate of glycosidase-digests of chondroitinase I; 6 , filtrate of glycosidases; 7 , filtrate of glycosidasedigests of chondroitinase III.

chondroitinase II by the action of glycosidases. On the other hand, chondroitinase I was slightly converted into chondroitinase II and a new fraction of which isoelectric point was 5.2. In the paper chromatogram of the filtrates (Fig.9), a spot having a similar $R f$ value to that of Nacetylglucosamine was detected in the digests of the chondroitinases (both I and III) and glucose was detected in the digest of chondroitinase I.

Thus the sequence of the conversion with respect to the multiple forms of Arthrobacter chondroitinase may be summerized as the following scheme:

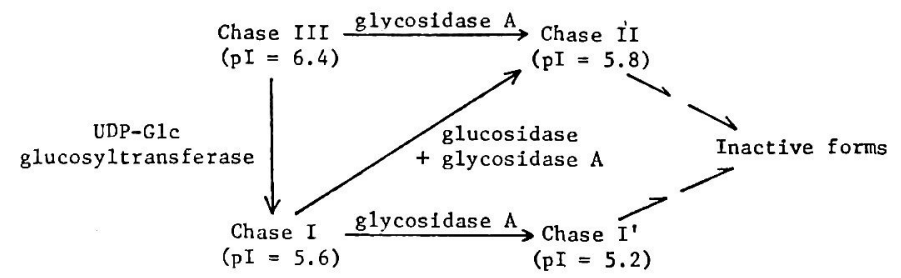

Scheme 1. Possible Mechanism of Conversion of the Multiple Forms of Arthrobacter Chondroitinase (Chase). 
In the scheme 1 Chase $I^{\prime}$ is another form than I, II and III, of which isoelectric point (pI) is 5.2 .

Several researchers have pursued the studies on the conversion of multiple forms of enzymes. $^{7 \sim 9)}$ Although these conversion experiments were performed in vitro, most of them were not of interconversion arising from the alteration of carbohydrate content but from sulfide-disulfide rearrangement. Therefore, our findings might propose a new concept with respect to the conversion of multiple forms of an enzyme.

It has been known that several kinds of multiple forms of enzymes are caused by posttranslational alterations ${ }^{10)}$ though they occur during cultivation of cells. Generally, it might be certified by the experiments of partially repressed cultivation. ${ }^{11)}$ As shown in this paper, the results of conversion experiments in vivo and in vitro, however, suggest that no more chondroitinase production takes place after $17 \mathrm{hr}$ of the cultivation time and the multiple forms of the chondroitinase are caused by post-translational alteration. Although the physiological significance of the multiple forms of the chondroitinase is still not clear, the stability of the enzyme against protease's action seems to have increased as the result of binding of glucose residues since chondroitinase I still remained after the total activity of chondroitinase had decreased and chondroitinase III had disappeared. While it had been recognized that the multiple forms of the enzyme scarcely differ from each other in the stability with respect $\mathrm{pH}$ and temperature and in the specific activity. ${ }^{11}$

Acknowledgments. The authors would like to express their appreciation to Dr. Takashi Okuyama and Mr. Takashi Ogura of Seikagaku Kogyo Co. for providing the glycosidases from Charonia lampas and for assisting them in preparation of an antibody. They are also grateful to Professor Saburo Fukui of Kyoto University for kind discussion and to Osaka Branch Office of Amco Co. for lending an electrophoretic apparatus (Multifore, LKB Produkter AB).

\section{REFERENCES}

1) K. Hiyama and S. Okada, Agric. Biol. Chem., 41, 1297 (1977).

2) K. Hiyama and S. Okada, J. Biol. Chem, 250, 1824 (1975).

3) J. J. Scheidegger, Int. Arch. Allerg., 7, 103 (1955).

4) N. Seno, K. Anno, K. Kondo, S. Nagase and S. Saito, Anal Biochem., 37, 197 (1970).

5) O. Vesterberg and H. Svensson, Acta Chem. Scand., 20, 820 (1966).

6) W. E. Trevelyan, D. P. Proctor and J. S. Harrison, Nature, 166, 444 (1950).

7) M. N. Blackburn, J. M. Chirgwin, G. T. James, T. A. Kempe, T. F. Parsons, A. M. Register, K.D. Schnackerz and E. A. Noltman, J. Biol. Chem., 247, 1170 (1972).

8) C. W. Lin, "Isozymes," ed. by C. L. Markert, Vol. I, Academic Press Irc., New York, 1975 p. 637.

9) J. M. Rodriguez and H. C. Pitot, Arch. Biochem. Biophys., 177, 185 (1976).

10) B. M. Turner, R. A. Fisher and H. Harris, "Isozymes," ed. by C. L. Markert, Vol. I, Academic Press Inc., New York, 1975, p. 781.

11) T. Komano, Plant Cell Physiol., 16, 659 (1975). 